\title{
Functional Conjugation of the Different Regulatory Responses to the Stress Stimuli in Healthy Human Subjects
}

\author{
Yurij G. Sukhovey ${ }^{1}$, Andrey V. Koptyug2* ${ }^{2}$, Tatjana A. Fisher ${ }^{3}$, Sergey A. Petrov ${ }^{3,4}$, \\ Evgenij L. Dotsenko 5 \\ ${ }^{1}$ Institute of Clinical Immunology, Siberian Division of Russian Academy of Sciences, \\ Tyumen, Russia \\ ${ }^{2}$ Sports Tech Research Centre, Mid Sweden University, Östersund, Sweden \\ ${ }^{3}$ Tyumen Research Centre, Siberian Division of Russian Academy of Sciences, Tyumen, Russia \\ ${ }^{4}$ Tyumen State Oil and Gas Institute, Tyumen, Russia \\ ${ }^{5}$ Tyumen State University, Tyumen, Russia \\ Email: i_yura62@mail.ru, ’andrei.koptioug@miun.se,Fitan72@mail.ru,tumiki@mail.ru, \\ dotsenko_e@bk.ru
}

Received 30 June 2016; accepted 9 August 2016; published 12 August 2016

Copyright (C) 2016 by authors and Scientific Research Publishing Inc.

This work is licensed under the Creative Commons Attribution International License (CC BY).

http://creativecommons.org/licenses/by/4.0/

(c) (i) Open Access

\begin{abstract}
Present article discusses the physiological mechanisms of the state employees adaptation during active training in temporary groups. It is suggested that adaptive mechanisms to adverse effects may be studied basing on the concept of functional isomorphism of the psychic and immune systems. Adaptive mechanisms were studied through the monitoring of the stress factors' impact upon the law enforcement officers when training outside the places of permanent deployment. The specific purpose of present study was to evaluate the physiological indicators of the psychic, immune and endocrine systems dynamics at different stages of adaptation of the live organism to a stressful situation, hoping to get better insight into possible relations between psychic and immune domains. Through monitoring of the dynamics of the endocrine and immune responses to the psychic stimuli, it was possible to correlate the stages of the stress onset to the phases of specific immune reactions. Strong correlations between the parameters characterizing activation of the psychic and immune responses support the hypothesis of the presence of "strong cooperation" between psychic and immune domains. It supports earlier hypothesis that we are monitoring different manifestations of the functioning of a complex inseparable psycho-immune meta-system.
\end{abstract}

\section{Keywords}

Stress, Immune and Psychic Domains, Endocrine System, Immune Response Stages, Functional

"Corresponding author. 


\section{Adaptation, Live Systems}

\section{Introduction}

Modern studies of the dynamics and adaptation of complex biological systems outline the need for the formation of new systemic approaches in dealing with biological and behavioral phenomena [1]-[11]. In particular, the studies of adaptive mechanisms maintaining system "balance" and integrity in various adverse conditions need to consider at least the following levels: mental, physiological and social. It is believed that these levels are interconnected through the "coupling" or interplay of the body regulatory systems (nervous, immune, endocrine and mental) [4]-[7] [12]. Network character of the immune system and its self-regulating properties [13]-[17] is already recognized and studied. It can be said that regulatory systems of the human body perform a common task maintaining the "dynamic homeostasis" (the term "homeorhesis" is more appropriate in this context, as the term "homeostasis" is referring to static situations [18]-[20] necessary for normal life and crucial for efficient adaptation of live organisms to change environmental conditions in order to preserve overall system integrity and identity [18]-[21].

At the moment, a considerable pool of evidence has been accumulated that:

- immune dysfunctions are often determined by psychogenic factors [2] [3] [22]-[26];

- immune reactions are involved in a joint self-regulation mechanisms of the live systems [6]-[12] [26]-[28];

- immunopathologic states can cause psychological discomfort [9] [29]-[32];

- there is a certain "parallelism" or a synchronization of functioning of the psychic and the immune systems, moreover it seems that we are dealing with a joint complex immune-psychic system, and are observing different manifestations of its functioning in two domains (also describing these manifestations using different meta-languages) [4]-[12] [21] [33] [34].

The presence of a common functional orientation of the adaptive reactions represented in two domains (psychic and immune) does not exclude functional coupling ("cross-talk", "bi-directional coupling", "communication", "partnership", "interplay") of these domains in matching scenarios and ways of solving the general problem [6] [7] [10]-[12] [21]. The specific factors triggering responses in these two domains are also known and the dynamics of such responses is extensively studied (though mainly separately in each domain). Here one can mention the studies on the stages of stress caused by psychogenic stimuli (psychic domain, [35]), and on the stages of immune response to the foreign antigen (immune domain [36] [37]). Taking into account probable "connection" between these two domains, it can be suggested that the immune system not only responds to the presence of infectious antigen but also to the psychogenic stimuli. And in order to prove if any conjugation or interrelation between these two domains actually exists, one should observe correlated dynamics of the immune system responses and the psychological distress factors. Moreover, if we are dealing with two coupled domains (conjugation hypotheses) or with a joint psycho-immune system (unification hypotheses) explicitly proposed earlier [12], one should observe certain reaction isomorphism and parallelism between the stages of psychological and physiological adaptation (in particular the specific immune response) in response to the stimulus in one of the domains.

To further test the relations between the psychic and immune domains, we have chosen to study the monitoring of stress-induced reactions in human subjects. It is known that specific immune response is one of the system protection strategies that human body has secured in the process of evolution [36] [38]-[40]. The stages of a specific immune response to a particular antigen and their duration are well studied. However, not much data describing the dynamics of the immune system when triggered via the psychic domain is available. It would be also of significant interest to compare the time line of the specific immune response stages when the reactions are triggered from psychic or immune domains.

The specific purpose of present study was to evaluate the physiological indicators of the psychic, immune and endocrine systems dynamics at different stages of adaptation of the live organism to a stressful situation, hoping to get better insight into possible relations between psychic and immune domains.

\section{Methods}

It is well known that special police force members are chosen to be very healthy and are routinely encountering 
stressful situations of different kind in their service [37] [41] [42]. Also they are regularly sent away from their home location for the intense training, where for a certain time they are becoming a part of a new team. In this situation they experience a number of different disturbing factors (such as different food, different lifestyle conditions, unusual activities etc.). The whole experience is commonly quite stressful but clearly not life threatening. The same time many other factors, which are hard to control in other research conditions, are almost "laboratory fixed" due to the military style discipline and organization of the whole exercise.

During this study 59 healthy male subjects were monitored from the moment they have arrived to start the training and until they finish it. According to the course selection rules strongly favoring homogenization we were able to include one of the groups entering the training without exceptions. Average age of the subjects was $23.5 \pm 0.71$ years, work experience 2 to 4 years; all subjects were coming from the same geographic region and have passed rigorous health checks according to the rules of their service. All subjects have signed the written consent forms. The consent forms and the plans for this research were approved by the commanding officers and Ethics Commission of the Institute of Immunology according to the formal documents issued by the Department of Health of Russian Federation.

The main focus of our research is aiming at the description of the interaction between the immune and psychic domains. Thus each specific "measurement" for the subject was related to the time (specific day of training), and consisted of the psychological survey, computer based tests (reaction, tiredness etc.) and the immune-endocrine tests.

Psychological tests were conducted in the middle of the day (after the morning training session), when the subjects were showing a high level of activity, and other conditions (communication, professional load, food) were rather stable. Following methods were used for the assessment: Lüscher color test [43], well-being-activitymood (WAM) test [44], socio-psychological climate (SPC) test modified as suggested by Maryin et al. [45].

Immune and endocrine tests were done using immune-ferment analysis (IFA). Functional activity of T-cells in the blood serum was estimated through the levels of regulatory cytokines: interleykin-4 (marker of the humoral immunity synthesized by the Th2 cells) and gamma interferon IFN- $\gamma$ (biomarker of the cellular immunity of the Th2 cells) using the immune ferment diagnostics assay by Vektor-Best (Novosibirsk, Russia [46]). Cortisol level was measured using the reagents by the Alcor-bio (St Petersburg, Russia [47]). Serotonin was measured using the enzyme immunoassay for the in-vitro diagnostic Serotonin ELISA by IBI-International (Hamburg, Germany [48]).

General functioning of the regulatory systems at the molecular level was estimated basing upon the levels of the serotonin (a neurotransmitter that regulates some of the mental processes) and the cortisol (bio-active glucocorticoid hormone of a steroid nature, which is involved in the development of stress reactions).

Because the research was aiming at detecting some parallelism in the psychic and immune domain responses (if any) each measurement was chosen to correspond to certain stages in the known timeline of the immune response [35] [49] [50].

Measurement \#1 was carried out on the 1st day of training. In the timeline of the pathogen-type stimulation of the immune domain it should correspond to the first or "immediate" phase of the immune response. It is characterized by a rapid response of the innate nonspecific immunity and activation of natural resistance factors (chemical, physical etc.). In the particular case this period was associated with the arrival at the location of new service (training), the actualization of the new social, psychological, professional and everyday life challenges.

Measurement \#2 was carried out on the 4th day of training. In the timeline of the pathogen-type stimulation of the immune domain it should correspond to the second or "early" phase of the immune response. It is characterized by the induction of early cellular response factors, which in turn trigger T-cell activity (as happens in the immune response to a foreign agent). In the overall live system dynamics this period is associated with an increased mobilization of different system resources such as immune, energetic and psychological (development of the internal stress in the stress management).

Measurement \#3 was carried out on the 14th day of training. In the timeline of the pathogen-type stimulation of the immune domain it should correspond to the third or "late" phase of the immune response. It is typically associated with switching from one antibody (IgM) type to another (IgG) type synthesis, and to the differentiation of immune responses while maintaining the original specificity. In the overall live system dynamics this period is associated with the stabilization in the resource mobilization (in terms of the stability of the professional, mental and physical stress), and the choice of strategies to respond to the stressful situation (increase or decrease in the live organism resistance). 
Measurement \#4 was carried out on the 21st day of training. In the timeline of the pathogen-type stimulation of the immune domain it should correspond to the fourth or "final" phase of the immune response. It is typically associated with the formation of immunological memory (ability to recall previous contact with the stimulus and respond to it in already known sway, faster and with greater strength); specificity (ability to recognize stimuli and to respond quickly and specifically, avoiding the chance of undifferentiated response); adequacy (the ability to respond specifically to the newly occurring factors). In the live system dynamics this period is associated with good adaptation (in the particular case to the new conditions of training within new group).

\section{Data Processing}

Following parameters were assessed using the WAM test: well-being-as a subjective perception of the degree of physiological and psychological comfort; activity-as a level of maintaining of vital meaningful interaction with the environment (includes chemical, physical, neural and mental activity); mood-as emotional responses to the impacts or stimuli of any nature.

Following parameters were assessed using the 8-color Lüscher test: vegetative factor-characterizing the energy balance of the mental activity of the organism (it is physiologically relevant to the sympathetic or parasympathetic neural system dominance); overall variability index-characterizing the stability of emotional background, and the total non-specific mental state, also allowing to predict the efficiency and success of performed activities.

Separate test was used to assess general socio-psychological climate and specifics of inter-personal relations


computer-based device for the fast assessment of the characteristics of the psychological state of the test subjects. This system is based on a personal computer with additional modules: a specialized psycho-diagnostic keyboard, a unit for psychomotor tests, a joystick, a foot pedal, and the headphones. This system has already proven its efficiency in the assessment of the psychological conditions and is widely used in Russian Federation for different professional assessments. The software part includes different diagnostic modules, including a set of classic tests (assessment of the actual mental state, professional aptitudes and mental abilities), as well as a large selection of activity-programmable (performance, psycho-physiological state) tests designed to evaluate the speed and accuracy of individual in performing perceptual, cognitive operations and movements. The socio-psychological climate was assessed by the results of the test scores achieved by the subjects and through questionnaires. Following interpretation of the socio-psychological climate was used: between 100 and 70 points- “favorable, healthy”; between 69 and 60 points_- “unstable but generally favorable”; between 59 and 50 points_- "not favorable enough”; below 49 points_-“unfavorable”.

Statistical analysis of the results was carried out using the software package "SPSS 11.5 for Windows" (including correlation analysis and Student's criterion tests).

\section{Results and Discussion}

Special police force members sent for the training to a new base, commonly far away from their home location, experience quite different conditions (social, hygienic, professional). In such situation multiple factors can be regarded as external stimuli triggering unspecific protective reactions (e.g. stress). Present studies were aiming at detecting parallelism in the psychic and immune domain responses (if any), so each measurement was chosen to correspond to certain stages in the known timeline of the stress onset stages [35] [49] [50] used in the modification adopted by Kulikov [52] putting them into the correspondence to the immune response stages.

Day 1 (first measurement) in this modified timeline corresponds to the "initial shock" (stage 1). At this point, the live object systems "estimate” the extent and quality of the social and psychological effects (risks, threats) due to the conditions related to the temporary environment (new location, social environment, food, team etc.). This suggestion is supported by the tests results. Vegetative factor values recorded for this period indicate optimal mobilization of physical and mental resources of the subjects and the trends to being proactive. Also overall variability index in measured parameters is very small, corresponding to very low unproductive mental stress with a proactive tendency (see Table 1, corresponding column “day 1"). The results of well-being-activitymood (WAM) tests reflect the high level of physiological, psychological and emotional comfort. The subjects have evaluated socio-psychological climate in the teams as mainly favorable and healthy. It suggests that a harmonious balance of business and emotional mediation of interpersonal perception and interaction between 
Table 1. Dynamics of the psychological parameter changes with the time. Results of the statistical analysis of experimental data. Statistical significance of the differences with the values at day 1 is $p<0.05$. WAM stays for well-being-activity-mood and SPC for socio-psychological climate tests correspondingly.

\begin{tabular}{cccccc}
\hline Method & Parameter & day $\mathbf{1}$ & day $\mathbf{4}$ & day 14 & day 21 \\
\hline $\begin{array}{c}\text { Lüscher color } \\
\text { test }\end{array}$ & Vegetative factor & $1.25 \pm 0.09$ & $1.44 \pm 0.15$ & $1.24 \pm 0.1$ & $1.42 \pm 0.09$ \\
& Total deviation & $10.24 \pm 0.58$ & $9.0 \pm 0.58$ & $9.88 \pm 1.02$ & $8.05 \pm 0.18$ \\
p & & & $<0.01$ \\
WAM test & Well-being & $6.12 \pm 0.06$ & $6.03 \pm 0.12$ & $6.1 \pm 0.51$ & $5.78 \pm 0.30$ \\
& Activity & $5.58 \pm 0.08$ & $5.5 \pm 0.11$ & $5.71 \pm 0.16$ & $6.0 \pm 0.18$ \\
\multirow{2}{*}{ SPC test } & Mood & $6.35 \pm 0.12$ & $6.27 \pm 0.18$ & $6.34 \pm 0.28$ & $6.25 \pm 0.22$ \\
\hline
\end{tabular}

members is achieved in the new teams.

When assessing the level of hormones in the blood serum significant excess of cortisol levels compared with generally accepted norms was found during this period of time, indicating a presence of certain psychoemotional tension (stress) (see Table 2). And according to the modern data cortisol has a depressing effect on cellular and humoral immunity and antibody formation, reducing the phagocyte activity of immune cells [53]-[55]. Simultaneously, serotonin level was within the healthy norm, but close to the lower limit values. At the same time serotonin has a proven significant effect on mood changes, irritability and cognitive processes (concentration, attention etc.). It is supported by certain correlation between the activity value measured in the WAM tests and the serotonin levels in the blood serum (correlation coefficient $r=0.405$ with statistical significance $\mathrm{p}<0.05$ ) (Table 3).

Changes in the level of hormones in the blood serum are accompanied by the characteristic response from the immune system. However, the ratio marking the functional state of the cell (IFN- $\gamma$ ) and humoral (IL-4) immunity, testifies to the balance among the various components of the immune system. Nevertheless, the level of IL-4 correlates with the overall variability index (Lüscher test) $(r=-0.338, p<0.05)$, and the level of socio-psychological climate (SPC test) with the level of IFN- $\gamma(r=0.332, p<0.05)$, respectively.

Towards day 4 (second measurement), subjects should enter the "alarm stage", which according to the literature is accompanied by stress manifesting itself physiologically with all functional systems of the live organism [25]. At this stage there was no acute changes detected in the psychic domain, as the changes in social and environment conditions were expected by the test subjects. Thus one can speak of a "planned" psychological reaction rather than an acute stress response. And as it is confirmed by the results of the study (Table 1 ) the subjects show a steady positive trend in the dynamics of psychic reactions.

This period is also characterized by a significant decrease in the serum levels of IFN $-\gamma(\mathrm{p}<0.001)$ and IL-4 ( $<<$ 0.05), markers of functional activity of both cellular and humoral immunity (Table 2). And considering that the ratio of the IFN- $\gamma$ and IL-4 concentrations reaches 3.85 at day 4, one can speak about the functional depression of humoral immunity. The same time the level of serum serotonin significantly increases from day 1 to day 4 (from $95.04 \pm 9.65$ to $121.7 \pm 10.21, \mathrm{p}<0.05$, Table 2), correlating with simultaneous changes in the WAM test activity $(r=0.519, p<0.05)$, state of health $(r=0.375, p<0.05)$ and vegetative factor $r=-0.313, p<0.05)$, respectively.

Basing on the above one can expect the improvements in the psycho-emotional state of the members of the newly formed teams. However, as follows from the results of psychological tests, changes in the psychic domain are not very pronounced. Also there are no significant changes in the serum cortisol levels (these levels strongly correlate with the mood parameter in the WAM test $(r=0.327$ at $\mathrm{p}<0.05)$.

Towards the 14th day (third measurement), the subjects enter the "resistance stage", characterized by increased resistance to stressor actions. Here are two basic response pathways known for this stage: the eustress, with a productive mobilization of all regulatory systems of the live organism; and distress [56], with the "over-regulation of the control systems" [45] [57] [58]. As shown by the results of our study, in this period, the level of cortisol in the blood serum is clearly reduced $(\mathrm{p}<0.05)$, which indicates the presence of the first response pathway (eustress). And at the time of a two-week stay in the new conditions vegetative factor of the test 
Table 2. Dynamics of the immune and endocrine parameter changes with the time: results of the statistical analysis. *normal-average levels for healthy subjects, as specified for the manufacturer of the corresponding immunoassays. Note the elevated but falling levels of cortisol from day 1 to 21, and strongly elevated ratio of concentrations IFN- $\gamma / \mathrm{IL}-4$ at day 14 .

\begin{tabular}{|c|c|c|c|c|c|}
\hline Parameter & day 1 & day 4 & day 14 & day 21 & normal $^{*}$ \\
\hline $\begin{array}{l}\text { Cortisol, } \\
\times 10^{-9} \mathrm{~mol} / \mathrm{l}\end{array}$ & $1120.0 \pm 85.12$ & $1028.0 \pm 72.1$ & $\begin{array}{c}831.13 \pm 69.19 \\
p<0.05\end{array}$ & $\begin{array}{c}704.6 \pm 63.89 \\
p<0.01\end{array}$ & $150-660$ \\
\hline $\begin{array}{l}\text { Serotonin, } \\
\times 10^{-9} \mathrm{~g} / \mathrm{ml}\end{array}$ & $95.04 \pm 9.65$ & $\begin{array}{c}121.7 \pm 10.21 \\
p<0.05\end{array}$ & $121.5 \pm 18.14$ & $\begin{array}{c}133.34 \pm 10.39 \\
p<0.05\end{array}$ & $40-400$ \\
\hline $\begin{array}{c}\text { IFN- } \gamma, \\
\times 10^{-12} \mathrm{~g} / \mathrm{ml}\end{array}$ & $1.17 \pm 0.15$ & $\begin{array}{c}0.81 \pm 0.05 \\
p<0.001\end{array}$ & $\begin{array}{c}1.31 \pm 0.08 \\
p<0.05\end{array}$ & $0.76 \pm 0.08$ & $0-15$ \\
\hline $\begin{array}{c}\text { IL-4, } \\
\times 10^{-12} \mathrm{~g} / \mathrm{ml}\end{array}$ & $1.03 \pm 0.1$ & $\begin{array}{c}0.21 \pm 0.09 \\
\mathrm{p}<0.01\end{array}$ & $\begin{array}{c}0.13 \pm 0.09 \\
p<0.01\end{array}$ & $0.95 \pm 0.01$ & $0-4$ \\
\hline $\begin{array}{c}\text { Ratio of concentrations } \\
\text { IFN- } \gamma / \text { IL- } 4\end{array}$ & 1.13 & 3.85 & 10.1 & 0.8 & \\
\hline
\end{tabular}

Table 3. Dynamics of the correlation coefficients between different experimentally measured factors.

\begin{tabular}{|c|c|c|c|c|}
\hline Parameters & day 1 & day 2 & day 14 & day 21 \\
\hline Cortisol/IL-4 & -0.338 & & & 0.507 \\
\hline Cortisol/Serotonin & & & 0.440 & \\
\hline Vegetative factor/Serotonin & & -0.313 & & -0.571 \\
\hline SPC level/IFN- $\gamma$ & 0.332 & & & \\
\hline General activity level/IL-4 & & & & 0.744 \\
\hline General activity level/Serotonin & 0.405 & 0.519 & & 0.446 \\
\hline General activity level/Cortisol & & & & -0.673 \\
\hline Well being factor/Serotonin & & 0.375 & & 0.428 \\
\hline Well being factor/Cortisol & & & & -0.469 \\
\hline Mood/Cortisol & & 0.327 & & \\
\hline
\end{tabular}

subjects was restoring to the original level (same as on day 1). Well-being, activity and mood parameters measured by WAM test were remaining high, which is also accompanied by the improvement of socio-psychological climate in the teams (see Table 1). This testifies to the positive dynamics of the psychic state, with the eustress as the choice of response pathway to the stressor. The blood serum serotonin levels are also stable between days 4 and 14 indicating the productive mobilization of the psychic domain activity. It is supported by the correlation between the index of overall variability index (reflecting the unproductive psychological stress) and the serotonin level $(r=0.440$ with $\mathrm{p}<0.05)$.

Differentiation of the immune response in this phase is characterized by reduction of the functional activity of the cellular component of the immune system, and the serum concentration of IFN- $\gamma$ is significantly increasing between days 4 and 14. At the same time, the concentration of IL-4 in the blood serum, which has already decreased between days 1 and 4, decreases even further towards day 14. This constitutes further depression of the humoral immunity, increasing the imbalance between cellular and humoral immune system components, since the ratio of the cytokines (IFN- $\gamma / \mathrm{IL}-4$ ) is increasing from 3.85 at day 4 to 10.1 at day 14 .

The 21st day (fourth measurement) should correspond to a complete adaptation of all functional systems of the live organism. Vegetative factor seems to grow between the days 14 and 21, but the changes are not very significant as the value keeps close to its value measured for day 4. It is clear that the dynamics of the vegetative factor normalization (Figure 1) is characterized by reduction of the energy balance of the body, setting on productive activities, which corresponds to the predominance of the parasympathetic division of the autonomic nervous system.

At this stage the overall variability index measured in the Lüscher test (reflecting the unproductive stress reaction) is significantly reducing as compared to all other stages (days $1,4,14$ ), which is accompanied by the 


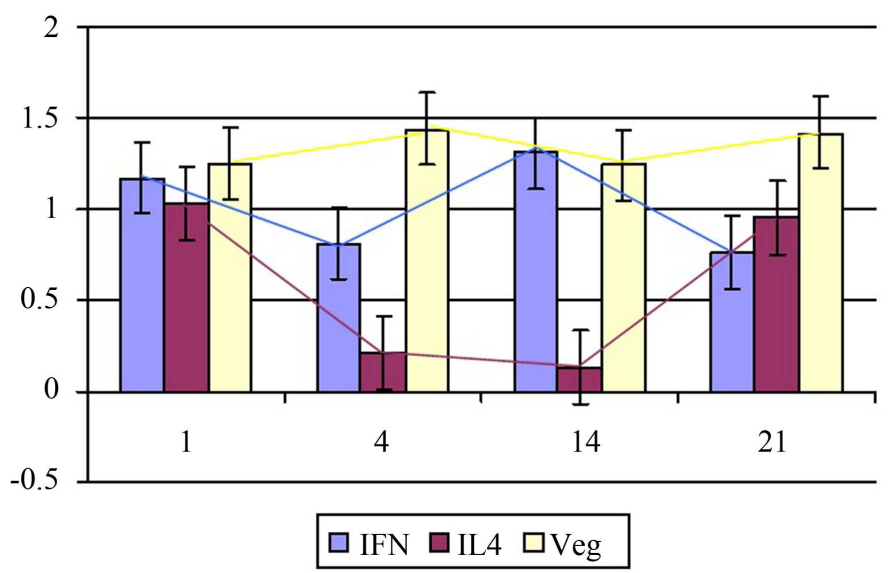

Figure 1. Experimentally recorded dynamics of the vegetative factor and functional activity of cellular and humoral immune system. IFN stays IFN- $\gamma$, Veg-Vegetative Factor. Average values for the whole subject group.

stabilization of the psycho-emotional state (health, activity, mood) and qualitative improvement of the socio-psychological climate in the teams (highest value for all measurements, see Table 1). This reflects the satisfaction of the subjects by their acquired status in the teams, by the environment at new location, and by the relationships with colleagues (both in terms of "horizontal", e.g. relations with the peers, and "vertical", e.g. relations with the superiors), and the prospects for further professional growth.

In this stage of adaptation the blood serum cortisol levels are returning to the values close to the upper boundaries of the 'norm'. But taking into account the specifics of the subject selection (special police force members); these values may simply represent the 'norm' for this population sub-group, routinely and continuously dealing with extreme situations. In turn, the functional state of the immune system, is also restored to the original level (Figure 1), with the ratio of the cytokines (IFN- $\gamma / \mathrm{IL}-4$ ) returning to parity.

This period is also characterized by the strongest parameter correlations. Overall variability index measured in the Lüscher test correlates with the level of IL-4 $(r=0.507, p<0.05)$; vegetative factor (Lüscher test) correlates with the blood serum serotonin level $(r=-0.571, \mathrm{p}<0.05)$; well-being factor (WAM test) correlates with the blood serum serotonin $(r=0428, \mathrm{p}<0.05)$ and cortisol $(\mathrm{r}=-0.469, \mathrm{p}<0.05)$ levels; the rate of activity is closely correlated with the levels of IL-4 $(r=0.744, p<0.001)$, serotonin $(r=0.446, p<0.05)$, and cortisol $(r=$ $-0.673, \mathrm{p}<0.001)$.

The results of present study show that psycho-immuno-endocrine interactions are strongly associated with the dynamic upkeep of the homeorhetic balance under the disturbances from the external and internal stimuli. One can also conclude that within the implementation of this regulatory mechanism either the psychic, immune and endocrine systems are acting jointly or represent different aspects of a single complex meta-system [12] [21]. The latter suggestion seems quite feasible, as the level of "cooperation" demonstrated within the mechanisms attributed to the psychic, immune and endocrine domains is quite significant. Another argument in favor of much deeper than earlier appreciated integration of the mechanisms supposedly belonging to three different domains is the "re-distribution of the resources" across the domains (Figure 1). Also the psycho-emotional state, which in turn affects the vegetative factor levels, is largely associated with the activity levels of the cellular immunity (reflected in the levels of blood serum IFN- $\gamma$ ). This once again suggests that psychic and immune domain mechanisms, in fact, are at least deeply coupled and function in perfect balance [12] [21]. Probably, these systems interact in a positive feedback manner: the mobilization of psychic domain protection mechanisms acts as a trigger for the immune defense ones, and vice versa. As a result, one can hypothesize that social and living conditions, as well as psychological and physiological (e.g., immune) adaptation and "life-support" mechanisms act in coordination or jointly, responding to the external and internal risk factors.

Table 4 illustrates a qualitative correspondence of the stages of different adaptation mechanisms responding to the specific and unspecific stimuli across three domains (psychic, immune, endocrine). These stages are related to the ones of the stress reaction onset, as it is believed that stress is a universal mechanism ensuring not 
Table 4. Correspondence of adaptive response phases in different domains as a reaction to risk stimuli.

\begin{tabular}{|c|c|c|c|c|}
\hline \multirow{2}{*}{$\begin{array}{c}\text { Phases of } \\
\text { stress } \\
\text { onset }\end{array}$} & \multirow{2}{*}{$\begin{array}{l}\text { Social and behavioral } \\
\text { domain }\end{array}$} & \multirow{2}{*}{$\begin{array}{c}\text { Individual psychological } \\
\text { domain }\end{array}$} & \multicolumn{2}{|c|}{ Physiology domain } \\
\hline & & & $\begin{array}{c}\text { Live organism response } \\
\text { level }\end{array}$ & Immune response level \\
\hline 1 & $\begin{array}{l}\text { Situational uncertainty } \\
\text { regarding social } \\
\text { risk factors }\end{array}$ & $\begin{array}{l}\text { Primary shock response } \\
\text { to the damaging effects }\end{array}$ & $\begin{array}{l}\text { Fast adaptation } \\
\text { preparation of the system } \\
\text { and resource mobilization }\end{array}$ & $\begin{array}{c}\text { Immediate phase } \\
\text { nonspecific (congenital) } \\
\text { protection mechanisms }\end{array}$ \\
\hline 2 & $\begin{array}{l}\text { Sampling of possibilities } \\
\text { Within different aspects } \\
\text { of social situation }\end{array}$ & $\begin{array}{c}\text { Alarm stage } \\
\text { general undirected activity }\end{array}$ & $\begin{array}{c}\text { Transient adaptation } \\
\text { transient period: from fast to } \\
\text { long-term adaptation } \\
\text { mechanisms }\end{array}$ & $\begin{array}{c}\text { Early phase } \\
\text { switching to different } \\
\text { specific response } \\
\text { mechanisms }\end{array}$ \\
\hline 3 & $\begin{array}{c}\text { Forming the intentions } \\
\text { choosing adequate vector } \\
\text { of activities }\end{array}$ & $\begin{array}{c}\text { Resistance stage } \\
\text { mobilization of the energy } \\
\text { and structural resources of } \\
\text { live organism }\end{array}$ & $\begin{array}{l}\text { Long-term adaptation } \\
\text { activation of structural } \\
\text { homeostatic mechanisms, } \\
\text { active functioning under } \\
\text { new conditions }\end{array}$ & $\begin{array}{l}\text { Late phase } \\
\text { Switching of the antibody } \\
\text { synthesis from IgM to IgG }\end{array}$ \\
\hline 4 & $\begin{array}{l}\text { Reduction of social } \\
\text { activity }\end{array}$ & $\begin{array}{c}\text { Exhaustion state } \\
\text { (distress) } \\
\text { apathy, tiredness, } \\
\text { depression-lake states etc. }\end{array}$ & $\begin{array}{l}\text { Exhaustion of the } \\
\text { protective and } \\
\text { adaptation capacity } \\
\text { maximal loading of the } \\
\text { dominating systems in } \\
\text { process of adaptation }\end{array}$ & $\begin{array}{c}\text { Completeness of } \\
\text { the immune response } \\
\text { Immunological memory } \\
\text { formation }\end{array}$ \\
\hline
\end{tabular}

only the survival under adverse conditions, but providing an adaptation to these conditions [59]. Each of the adaptation responses is coming with certain "energy cost", e.g. to perform corresponding activity live organism needs to use some of its resources (reserves) [60]. With such comparison it becomes possible to see some common trends and patterns for different levels of adaptation in different domains, though similar trends are often described in different ways (using different meta-languages).

Probably in the process of evolution a complex mechanism that selects necessary "response programs" was developed, helping to survive and adapt to different conditions. It is commonly accepted that complex living organisms possess both simpler particular response mechanisms and higher level generalized ones (using common, universal principles) helping to cope with the variety of changes in their environment [61].

\section{Conclusions}

Functional activities of the psychic, immune and endocrine systems (domains) in reaction to the stress stimuli are closely interrelated, which is reflected in the close correlations of characteristic parameters and their trends measured experimentally. Basing on the data available to the moment, it is also possible to conclude that the response in one domain (or the stimulus initiating such response) modulates corresponding response in another domain, increasing the functionality limits and the capacity of the overall system to sustain the dynamic equilibrium (homeostatic balance, homeorhesis [18] [19] [59]). Therefore, traditional notation of the psychic, immune and endocrine system can be (and most probably should be) substituted by the notation of the corresponding psychic, immune and endocrine domains reflecting specific features and characteristic response mechanisms of the complex, unified regulatory meta-system "live organism". And the integrity (similarity, parallelism, synchronized timing) in the functioning of the regulatory mechanisms manifesting themselves in the changes detected in different domains is most probably governed by the high-level "centralized" interrelations. Strong correlation of such manifestations with the blood serum hormone levels points out to a possible central role of the coordinated activity of the sympathoadrenal (serotonin) and hypothalamic-pituitary-adrenal (cortisol) systems in triggering and driving adaptive responses across all major domains. On the other hand, changes in the blood serum cortisol levels may be the consequences rather than the causes of multiple process activation, reflecting the growing demands of the regulatory systems to the energy resources. It is known that the metabolic effects of cortisol are similar to the ones of adrenaline (both are triggering the release of energy resources [55]).

Thus it is possible to hypothesize that mobilization of energy and structural resources, and more efficient incorporation of cellular structures, including cells of the immune system happens under the influence of hormon- 
al system triggered by internal and external stimuli. And it turns out that system reaction to the stress factors "switches on" corresponding mechanisms aiming at effective adaptation to the changes. Interestingly, live systems have mechanisms allowing for the adaptation responses at different time scales (immediate, intermediate and long-term adaptation), which at the system level often points to the presence of different but coupled response mechanisms.

Results of present research demonstrate that even a small levels of psycho-emotional stress (stress factors were not extreme and were expected in advance: in our case-test subjects were aware of the changes in their environment) were capable of changing the level of cortisol and serotonin and were reducing the functional activity of specific parts of the immune system. It is known that the development of the immune response is mediated by T-helper lymphocytes, commonly used as the markers of humoral and cell immunity (IL-4 and IFN- $\gamma$ ). Monitoring blood concentration of these markers has shown that nonspecific response to the stimuli in the psychic domain also activates adaptive-search mechanisms maintaining overall system balance (homeostatic balance, homeorhesis). Through monitoring of the dynamics of the endocrine and immune responses to the psychic stimuli it is possible to correlate the stages of the stress onset (dynamics in the psychic domain), to the phases of specific immune reactions (dynamics in the immune domain). It is quite clear that immune responses are triggered by both psychic and infection stimuli, showing up as the T-cell response carried out with the participation of Th1 and Th2 lymphocytes. Established strong correlations between the parameters characterizing activation of the psychic and immune responses support the hypothesis of the presence of "strong cooperation" between two sub-systems. It also does not contradict more general hypothesis suggested earlier that we are monitoring different manifestations of the functioning of a complex inseparable psycho-immune meta-system [12]. Within latter hypothesis observed phenomena are the manifestations of a common mechanism reacting to various adverse factors, which can have a profound biological sense. As threatening factors are extremely diverse it is hardly possible to "store" all needed specialized and ready-to-go adaptation programs. More effective strategy in this case could be in simultaneous triggering of "centrally-supervised” adaptation control mechanisms creating a basis (metabolic, functional, structural) for a variety of adaptation strategies at different system levels [55].

In this multi-level adaptation strategy, psychic and immune domains play a central role in ensuring the survival and successful development of the live organism in all time scales (immediate, intermediate and long-term) of its dynamics. Attributing psychic and immune responses to different and separate sub-systems is most probably a result of the "reduction" at the early stages of constructing the models facilitating better understanding of a very complex live system functioning. The same time more and more facts, including the results of present research, are pointing out to the fact that two domains (psychic and immune) are functioning in certain synchronism and are intricately coupled [12]. It is not possible to speculate at the moment if these two domains were separate at the early stages of evolution and later developed similar regulatory mechanisms and behavioral patterns, or this happened through diversification and specialization of the mechanisms originally being a part of a single system, or these domains have evolved as inseparable entity all the time. But to the moment more and more facts are indicating that we deal with a complex meta-system, which not only provides multiple "layers of protection" and keeps the "library" of successfully used strategies, but also is capable of creating and adjusting new strategies helping to protect live organism against overload and destruction. And in the adaptation process of highest priority (support of life, dynamic homeostasis, or homeorhesis [18] [19] [59]), live organism invokes all major resources, including the mechanisms functioning across the psychic, immune and endocrine domains.

\section{Acknowledgements}

Authors are grateful to Prof. V. P. Melnikov for support and valuable discussions

\section{References}

[1] Barnard, C.J., Behnke, J.M., Gage, A.R., Brown, H. and Smithurst, P.R. (1997) Immunity Costs and Behavioral Modulation in Male Laboratory Mice (Mus musculus) Exposed to the Odours of Females. Physiology \& Behavior, 62, 857-866. http://dx.doi.org/10.1016/S0031-9384(97)00249-7

[2] Sidor, M.M. (2009) Behavioural and Molecular Outcomes of Early Life Immune Challenge in Mice. PhD Dissertation, McMaster University, Hamilton, Ontario.

[3] Engler, H., Bailey, M.T., Engler, A., Stiner-Jones, L.M., Quan, N. and Sheridan, J.F. (2008) Interleukin-1 Receptor Type 1-Deficient Mice Fail to Develop Social Stress-Associated Glucocorticoid Resistance in the Spleen. Psychoneu- 
roendocrinology, 33, 108-117. http://dx.doi.org/10.1016/j.psyneuen.2007.10.007

[4] Conrad, C.D. (2011) The Handbook of Stress: Neuropsychological Effects on the Brain. Wiley-Blackwell, Chichester.

[5] Quan, N. and Banks, W.A. (2007) Brain-Immune Communication Pathways. Brain, Behavior, and Immunity, 21, 727-735. http://dx.doi.org/10.1016/j.bbi.2007.05.005

[6] Ziemssen, T. and Kern, S. (2007) Psychoneuroimmunology-Cross-Talk between the Immune and Nervous Systems. Journal of Neurology, 254, II8-II11. http://dx.doi.org/10.1007/s00415-007-2003-8

[7] Wrona, D. (2006) Neural-Immune Interactions: An Integrative View of the Bidirectional Relationship between the Brain and Immune Systems. Journal of Neuroimmunology, 172, 38-58.

http://dx.doi.org/10.1016/j.jneuroim.2005.10.017

[8] Pacheco-López, G. and Bermúdez-Rattoni, F. (2011) Brain-Immune Interactions and the Neural Basis of Disease-Avoidant Ingestive Behaviour. Philosophical Transactions of the Royal Society B, 366, 3389-3405. http://dx.doi.org/10.1098/rstb.2011.0061

[9] Doenlen, R.A. (2008) Fingerprints of Neural Activity after Peripheral Immune Challenges: An Experimental Study on the Communication between the Immune and Central Nervous Systems. PhD Dissertation, École Polytechnique Fédérale de Lausanne, Lausanne.

[10] Shrestha, R., Millington, O., Brewer, J. and Bushell, T. (2013) Is Central Nervous System an Immune-Privileged Site? Kathmandu University Medical Journal, 41, 102-107.

[11] Dotsenko, E.L., Bogdanova, M.V., Fisher, T.A., Petrov, S.A. and Suhovey, Yu.G. (2013) Synchronization of Immune and Psychic Systems Associated with Social Stress. Proceedings International Conference on Integration and Innovation in Science and Education, Prague, Czech Republic, 7-14 April 2013, 324-328. http://dx.doi.org/10.12955/cbup.2013.53

[12] Suhovey, Yu.G., Koptyug, A.V., Petrov, S.A., Dotsenko, E.L. and Fisher, T.A. (2014) Psycho-Immune Partnership in the Dynamic Responses of Living System. International Journal of Life Science and Medical Research, 4, 57-70. http://dx.doi.org/10.5963/LSMR0405001

[13] Kim, P.S., Levy, D. and Lee, P.P. (2009) Modeling and Simulation of the Immune System as a Self-Regulating Network. Methods in Enzymology, 467, 79-109. http://dx.doi.org/10.1016/S0076-6879(09)67004-X

[14] Perelson, A.S. (1989) Immune Network Theory. Immunological Reviews, 110, 5-36. http://dx.doi.org/10.1111/j.1600-065X.1989.tb00025.x

[15] Jerne, N.K. (1974) Towards a Network Theory of the Immune System. Ann. Immunol., 125C, 373-389.

[16] De Boer, R.J. and Perelson, A.S. (1990) Size and Connectivity as Emergent Properties of a Developing Immune Network. Journal of Theoretical Biology, 149, 381-424. http://dx.doi.org/10.1016/S0022-5193(05)80313-3

[17] Varela, F.J. and Stewart, J. (1990) Dynamics of a Class of Immune Networks: Global Stability of Idiotype Interactions. Journal of Theoretical Biology, 144, 93-101. http://dx.doi.org/10.1016/S0022-5193(05)80301-7

[18] Waddington, C.H. (1957) The Strategy of the Genes: A Discussion of Some Aspects of Theoretical Biology. George Allen and Unwin, London.

[19] Waddington, C.H. (1968) Towards Theoretical Biology. Nature, 218, 525-527. http://dx.doi.org/10.1038/218525a0

[20] Surh, C.D., Boyman, O., Purton, J.F. and Sprent, J. (2006) Homeostasis of Memory T Cells. Immunological Reviews, 211, 154-163. http://dx.doi.org/10.1111/j.0105-2896.2006.00401.x

[21] Suhovey, Y.G. and Dotsenko, E.L. (2012) Immanence and Isomorphism of the Psychic and the Immune Systems. Transactions of the Ural Medical Academic Sciences, 4, 62-63. (In Russian)

[22] Loskutova, L.V., Idova, G.V. and Gevorgyan, M.M. (2007) The Immune Response in Wistar Rats with High and Low Situational Anxiety. Bulletin of Experimental Biology and Medicine, 11, 549-551. (In Russian)

[23] Devoyno, L.V., Idova, G.V. and Alperina, E.L. (2009) Psycho-Neuro-Immunomodulation. Behavior and Immunity. The Role of "Neurotransmitter Settings and Brain”. Science, Novosibirsk. (In Russian)

[24] Tenditnik, M.V., Shurlygina, A.V., Melnikova, E.V. and Kudryavtseva, N.N. (2004) Changing the Composition of Lymphocyte Subpopulation of Mice Immune Organs under the Influence of Chronic Social Stress. I.M. Sechenov's Russian Physiological Journal, 12, 1522-1529. (In Russian)

[25] Kudryavtseva, N.N. (2006) Chapter 2: The Psychopathology of Repeated Aggression: A Neurobiological Aspect. In: Morgan, J.P., Ed., Perspectives on the Psychology of Aggression, Nova Science Publishers, Inc., New York, 35-64.

[26] Lyte, M., Nelson, S.G. and Thompson, M.L. (1990) Innate and Adaptive Immune Responses in a Social Conflict Paradigm. Clinical Immunology and Immunopathology, 57, 137-147. http://dx.doi.org/10.1016/0090-1229(90)90029-P

[27] Bogdanova, M.V. and Dotsenko, E.L. (2010) Self-Identity: From Protection to Creation: A Monograph, Tymen. (In Russian) 
[28] Kim, P.S., Lee, P. and Levy, D. (2007) Modeling Regulation Mechanisms in the Immune System. Journal of Theoretical Biology, 246, 33-69. http://dx.doi.org/10.1016/j.jtbi.2006.12.012

[29] Kolesnikov, O.L., Dolgushin, I.I., Seljanina, G.A., Shadrina, I.V., Shalashova, M.A. and Kolesnikova, A.A. (2006) Influence of the Reactive Anxiety Level on the Immune System and Metabolism. Bulletin of Experimental Biology and Medicine, 142, 185-187. (In Russian)

[30] Dotsenko, E.L. and Fisher, T.A. (2010) Psychosomatic Response to the Introduction of Micro-Organisms in Mice. Bulletin of the Tyumen State University, 5, 120-128. (In Russian)

[31] Capuron, L., Miller, A. and Irwin, M.R. (2007) Psychoneuroimmunology of Depressive Disorder: Mechanisms and Clinical Implications. Psychoneuroimmunology, 1, 509-530. http://dx.doi.org/10.1016/B978-012088576-3/50030-7

[32] Park, J.E., Kim, S.W., Park, Q., Jeong, D.U. and Yu, B.H. (2005) Lymphocyte Subsets and Mood States in Panic Disorder Patients. Journal of Korean Medical Science, 20, 215-219. http://dx.doi.org/10.3346/jkms.2005.20.2.215

[33] Fisher, T.A. (2012) Psychological and Immune Responses to Short-Term Low Temperature Exposure. Bulletin of the Ural Medical Academic Sciences, 4, 66-67. (In Russian)

[34] Fisher, T.A. and Petrov, S.A. (2012) The Impact of Stress Loads on the Immuno-Psychological Characteristics. Bulletin of the Ural Medical Academic Sciences, 4, 65-66. (In Russian)

[35] Selye, G. (1960) Essays on Adaptation Syndrome. Medgiz, Moscow. (In Russian)

[36] Trunova, G.V., Makarova, O.V., Serebryakov, S.N. and Diatroptov, M.E. (2003) Comparative Evaluation of Cytokine Production by Splenocytes in Mice of the Lines C57BL/6 and BALB/C during Low Temperature Exposure. Physiology and Pathology of the Immune System, 5, 160-161. (In Russian)

[37] Aleksandrov, D.A. (2013) Theoretical Basis for the Police Officers Professional Adaptation Studies. Pedagogics of the Law Enforcement, 4, 12-16. (In Russian)

[38] Kimbrell, D.A. and Beutler, B. (2001) The Evolution and Genetics of Innate Immunity. Nature Reviews Genetics, 2, 256-267. http://dx.doi.org/10.1038/35066006

[39] Hoffman, J.A. and Reichhart, J.-M. (2005) Drosophila Innate Immunity: An Evolutionary Perspective. Nature Immunology, 3, 121-126. http://dx.doi.org/10.1038/ni0202-121

[40] Kim, D.H. and Ausube, F.M. (2005) Evolutionary Perspectives on Innate Immunity from the Study of Caenorhabditis elegans. Current Opinion in Immunology, 17, 4-10. http://dx.doi.org/10.1016/j.coi.2004.11.007

[41] Zozulya, G.A. (2011) Development of Professional Adaptation and Psychological Readiness of Young UNPO Employees to Act in Extreme Conditions. Pedagogics of the Law Enforcement, 4, 14-20. (In Russian)

[42] Fisher, I.V. (2014) Influence of Shooting from Service Weapons on the Psycho-Emotional State of the Professionals Taking Initial Training Courses. Bulletin of the Ministry of Russian Internal Affairs, 1, 166-168. (In Russian)

[43] Lüscher, M. (1972) The Lüscher Colour Test. Pan Books, London.

[44] Doskin, V.A., Lavrentyeva, N.A., Sharaj, V.B. and Miroshnikov, M.P. (2009) Questioner: Well-Being-Activity-Mood. In: Barkanova, O.V., Ed., Diagnostic Methods for the Emotional Sphere: Psychological Workshop. Series: Modern Psychology, Vol. 2, Litera-Print, Krasnoyarsk, 7-22. (In Russian)

[45] Maryin, M.I., Lovchan, S.I., Ivanihina, I.V. and Shmakova, S.G. (2001) Test for the Overall Assessment of Psychological Climate. Ministry of Russian Internal Affairs, Moscow. (In Russian)

[46] Vector Best Products (2016). http://www.vector-best.ru/prod/index.php?pcat=ifa\&gid=145

[47] Alcor Bio Products (2016). http://www.alkorbio.ru/funktsiyanadpochechnikov/10001steroidifakortizol.html

[48] Product Serotonin ELISA (2016). http://www.ibl-international.com/en/serotonin-elisa

[49] Aber, R., Felten, D. and Cohen, N. (1990) Psychoneuroimmunology. 2nd Edition, Academic Press, Cambridge, 1218.

[50] Daruna, J.H. (2012) Introduction to Psychoneuroimmunology. 2nd Edition, Academic Press-Elsevier, Cambridge.

[51] Product Multipsychometer (2016). http://www.multipsychometr.ru/izdel/mpm/

[52] Kulikov, Y.B. (2002) Oxidative Stress (Physiology, Pathogenesis, Correction). Proceedings of the Conference: Compensatory and Adaptive Processes: Fundamental and Clinical Aspects, Novosibirsk, 4-6 November 2002, 43-44. (In Russian)

[53] Hellhammer, D.H., Wust, S. and Kudielka, B.M. (2009) Salivary Cortisol as a Biomarker in Stress Research. Psychoneuroendocrinology, 34, 163-171. http://dx.doi.org/10.1016/j.psyneuen.2008.10.026

[54] Leserman, J. (2008) Role of Depression, Stress, and Trauma in HIV Disease Progression. Psychosomatic Medicine, 70, 539-545. http://dx.doi.org/10.1097/PSY.0b013e3181777a5f

[55] Abramov, V.V., Markova, E.V., Korotkova, N.A. and Kozlov, V.A. (2002) Modulation by Immunocompetent Cells of the Orienting-Exploratory Behavior of (CBAxC57BI/6)F1 Mice. Bulletin of Experimental Biology and Medicine, 134, 
319-321. (In Russian)

[56] Suedfeld, P. (1997) Reactions to Societal Trauma: Distress and/or Eustress. Political Psychology, 18, 849-861. http://dx.doi.org/10.1111/0162-895X.00082

[57] Le Fevre, M., Matheny, J. and Kolt, G.S. (2003) Eustress, Distress, and Interpretation in Occupational Stress. Journal of Managerial Psychology, 18, 726-744. http://dx.doi.org/10.1108/02683940310502412

[58] Machac, M., Machacová, H., Stárka, L. and Hampl, R. (1987) Changes in Cortisol Level in Saliva Following Relaxation-Activation Autoregulative Intervention. Activitas Nervosa Superior, 29, 159-163.

[59] Poletaev, A.B., Morozov, S.G. and Kovalev, I.E. (2002) Regulatory Metasystem (Immuno-Neuro-Endokrine Regulation of Homeostasis). Medicine, Moscow. (In Russian)

[60] Pokrovsky, V.M. and Korotko, G.F. (2003) Human Physiology. Medicine, Moscow. (In Russian)

[61] Poletaev, A.B. (1995) Regulatory Antibodies. In: Monoclonal Antibodies in Neural Biology, Offset, Novosibirsk, 3747.

\section{Submit or recommend next manuscript to SCIRP and we will provide best service for you:}

Accepting pre-submission inquiries through Email, Facebook, LinkedIn, Twitter, etc.

A wide selection of journals (inclusive of 9 subjects, more than 200 journals)

Providing 24-hour high-quality service

User-friendly online submission system

Fair and swift peer-review system

Efficient typesetting and proofreading procedure

Display of the result of downloads and visits, as well as the number of cited articles

Maximum dissemination of your research work

Submit your manuscript at: http://papersubmission.scirp.org/ 